\title{
Electromyography Diagnosis and Treatment with Botulin Toxin for Hemi facial Post Paralytic Spasm, Case Report
}

\author{
Carrillo Rivera Jorge Arnulfo ${ }^{1, *}$, Ferraez Castañeda Carolina ${ }^{1}$, Daniel Flores Rodríguez ${ }^{3}$, \\ Aguirre Solorio Berenice ${ }^{4}$, Tolentino Gonzalez Christian Stefan ${ }^{5}$, Juaréz Manrique Jesus ${ }^{6}$, \\ Hector Jovany Inzunza ${ }^{7}$, García Luis Diana ${ }^{8}$, Medina Andrade Luis Angel' , Vallejo Ramirez \\ José Eduardo ${ }^{9}$, Garcia Barajas Guillermo Antonio ${ }^{9}$ \\ ${ }^{1}$ Stomatologist with specialization in oral and maxillofacial surgery, General Hospital "Dr. DaríoFernández \\ Fierro", ISSSTE, México City \\ ${ }^{2}$ Oral Surgery Resident, Regional Hospital Lic. Adolfo LópezMateos, ISSSTE, México city \\ ${ }^{3}$ General Surgery Resident, Veracruz General Hospital, México \\ ${ }^{4}$ Research and Postgraduate Unit of Michoacán University of San Nicolas Hidalgo, México \\ ${ }^{5}$ General Zone Hospital \#47 “Vicente Guerrero”, IMSS, México City, México \\ ${ }^{6}$ Maxillofacial Surgeon, Faculty of Higher Education Iztacala, UNAM, México \\ ${ }^{7}$ General Regional Hospital \#1, IMSS, Culiacan, México \\ ${ }^{8}$ Polanco Dental Specialties Center, México City, México \\ ${ }^{9}$ General Surgery Service, General Zone Hospital \#1A, IMSS, México City, México
}

\begin{abstract}
*Corresponding Author: Carrillo Rivera Jorge Arnulfo, Stomatologist with specialization in oral and maxillofacial surgery, General Hospital "Dr. DarioFernández Fierro”, ISSSTE, México City. Email: dr_jorque_carillo_cmf@hotmail.com
\end{abstract}

Abstract: Electromyography is the study of muscle activity and their motor units, to diagnose the changes in electrical transmission and assess the changes after treatment.

Postparalytic Hemifacial spasm is an involuntary hyperkinetic movement disorder that affects the muscles as a sequel of facial paralysis.

Botulinum toxin is a derivative of Clostridium Botulinum microorganism that reduces muscle contraction by acetylcholine release blockade in the presynaptic motor nerve terminal.

The aim of the present article is to know the electromyography activity of postparalytic hemifacial spasm in a patient after application of botulinum toxin.

Keywords: Electromyography, botulinum toxin, hemifacial spasms.

\section{INTRODUCTION}

Electromyography (EMG) is defined as the study of the muscle electrical activity for diagnosis and look out results after treatment. It could be divided in invasive and no invasive, the first is when an electrode is placed in the skin over the muscle, and invasive is when a mono polar needle with politetrafluoroetilene cover is introduced in the muscle to be studied. The bioelectrical potentials to be studied are amplified and showed in a cathode ray oscilloscope to complete the visual analysis in a screen ${ }^{1}$.
The postparalytic hemifacial spasm presents when the muscles innervated by the facial undergo an aberrant regeneration, generating epiphora and synchronous contraction. This spastic action could be very brief or persist as tonic contraction of several seconds. Differential diagnosis includes blepharospasm, facial myokimiasis, Meige syndrome and focal crisis ${ }^{2}$.

Electromyographically is described as fascicular potentials of the motor unit secondary to the spontaneous activation of individual motor muscle fibers. It could be observed in patients with partial and chronic denervation, secondary 
to neuromuscular diseases or sequelae of facial paralisis ${ }^{3}$.

\section{CASE REPORT}

A female patient of 57 years-old came to consult with a diagnosis of postparalytic hemifacial spasm of 10 years of evolution. She denies pathological background.

At physical exam she presented postparalytic hemifacial spasm in right superciliary, nasogenian and chin region.

Initial electromyography showed a right facial nerve neuropathy with axonal degeneration grade III of House-Beckmann, a Botman and Jongkess moderated and Smith II paresis, with limitation of movements in frontal, orbicular and lip depressor muscles, with right temporal, zygomatic, buccal and marginal mandibular branches (Figure 1).

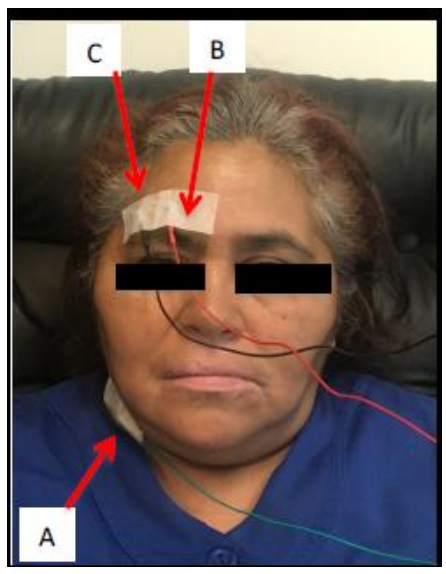

Figure1. A) Positioning the base electrode B) Positive Bipolar electrode y C) Negative electrode in the frontal muscle surface

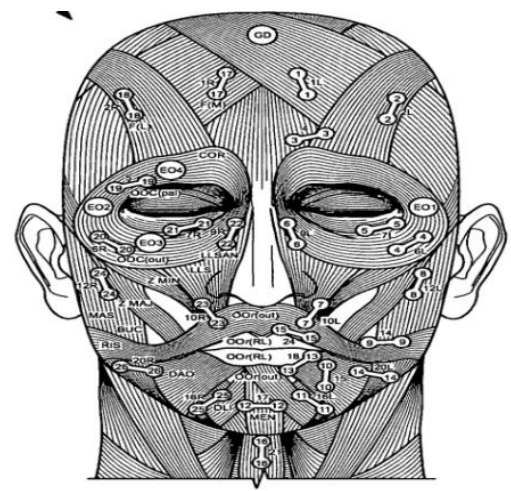

Figure2. Facial region map for the position of electrodes during electromyography

Electromyography signals detected in the left face muscles at rest (healthy side) were of $5 \mathrm{mV}$ with a frequency of $10 \mathrm{~Hz}$, but in the right face muscles (affected side) signals have a higher frequency of $40 \mathrm{~Hz}$, with increased spontaneous activity of motor units by the involuntary contraction of muscular fibers every 3 to 5 milliseconds (Fig 2).

The conclusion of this study was a higher involuntary contraction force (vertical wave amplitude) in the lips depressor and frontal muscles, a higher frequency between spasm in the orbicularis muscle eyelids and lips, and lasting contraction in the upper lip lift muscle (Figure 3, 4 y 5).

With the electromyography reported results type A botulin toxin Xeomeen ${ }^{\mathrm{MR}}$ was applied, 4 IU in the eyelid orbicular muscle, $6 \mathrm{IU}$ in the lip depressor muscle and chip, and $8 \mathrm{IU}$ in the frontal and upper lip lift.

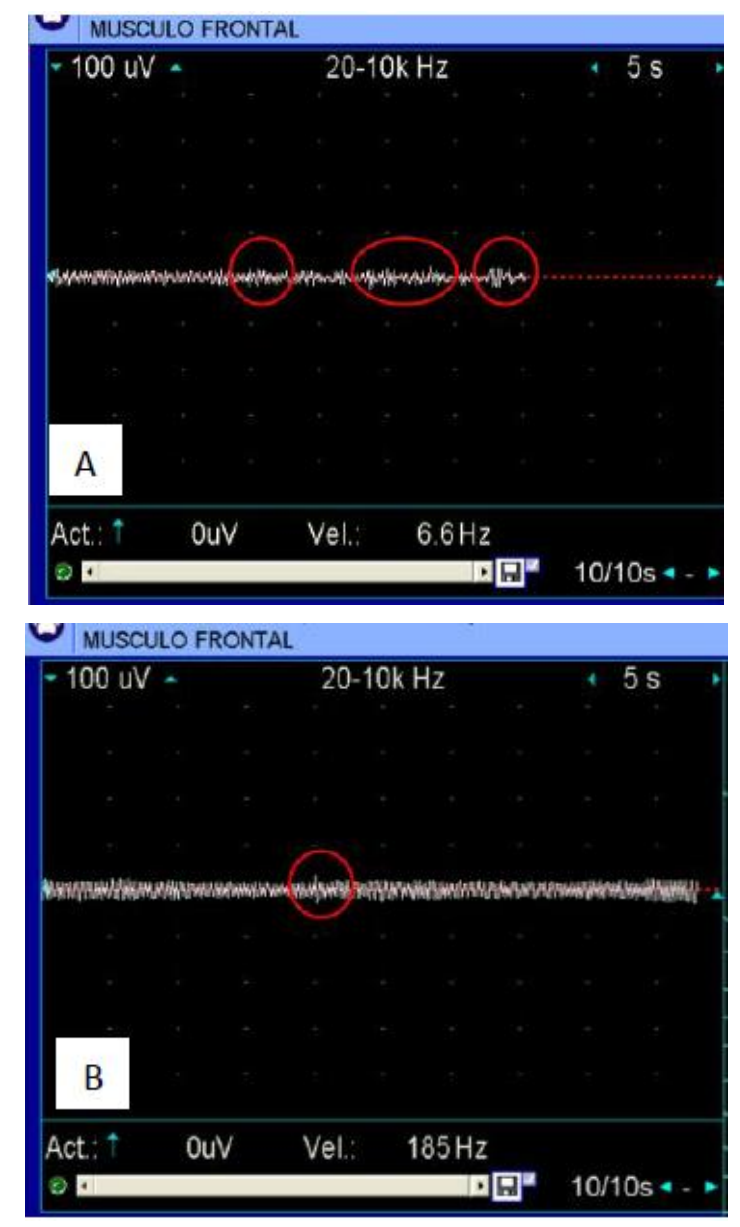

Figure3. A) Initial electromyography in the frontal muscle. B) Control electromyography 15 days after botulin toxin application in the frontal muscle.

During follow up at 15 daysthe control electromyography reports a fewer presence of involuntary movements in the affected muscles with an amplitude of $15 \mathrm{~Hz}$. The frequency improves significantly with a segment between spasm of more than 3 minutes. Although some abnormal characteristics in the driving unit were observed, the excitability of the muscle membrane improves, showing wide segments in the baseline. 
Electromyography Diagnosis and Treatment with Botulin Toxin for Hemi facial Post Paralytic Spasm, Case Report

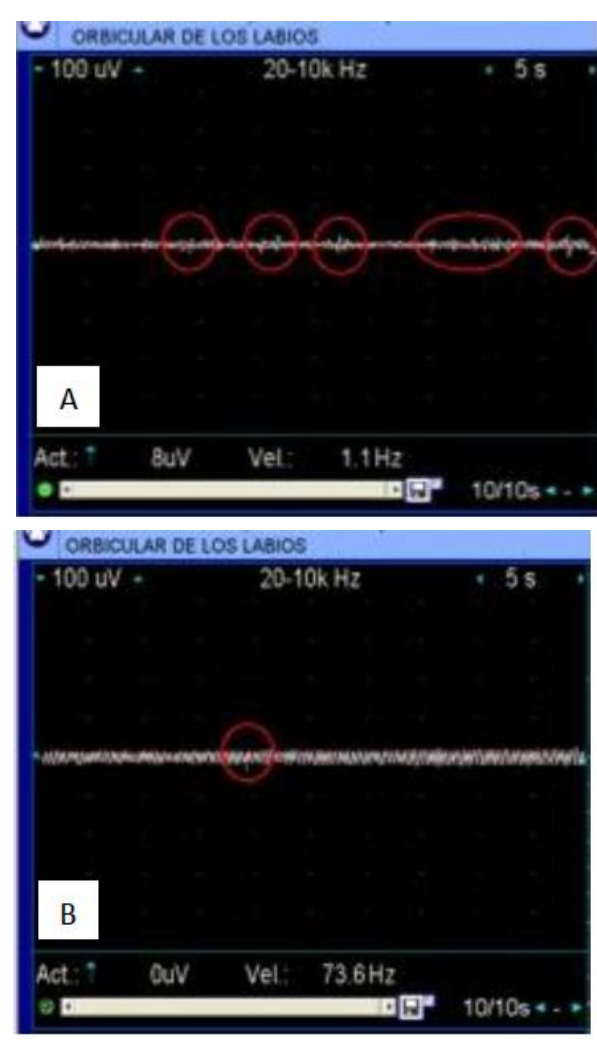

Figure4. A) Initial electromyography of the lip orbicular muscle B) Control electromyography 15 days after application of botulin toxin.in the lip orbicular muscle
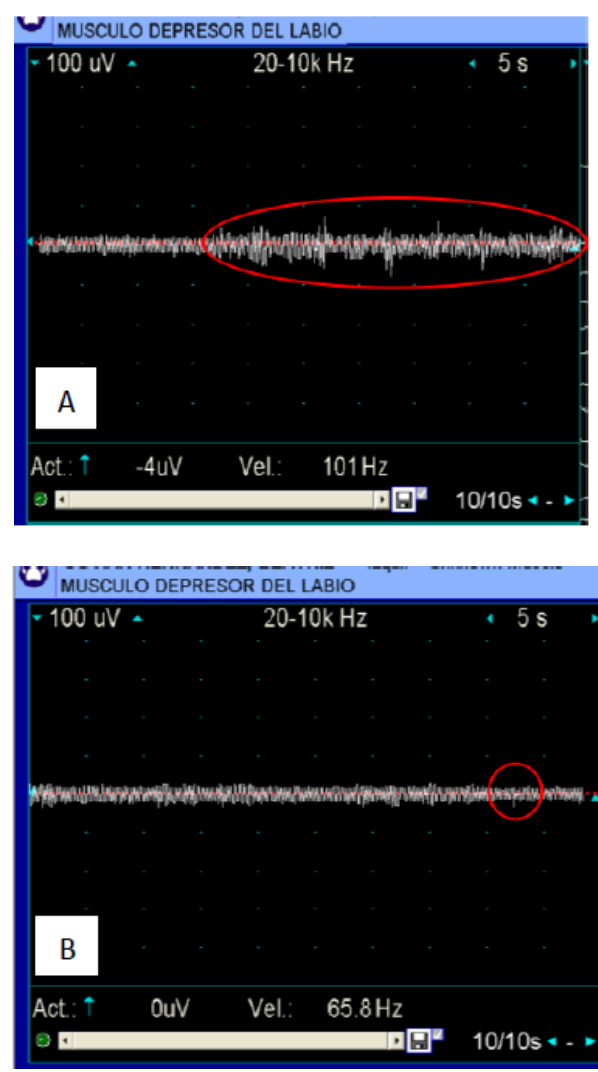

Figure5. A) Initial electromyography of the lip depressor muscle B) Control electromyography 15 days after application of botulin toxin in the lip depressor muscle

\section{DISCUSSION}

According to Jinnah, the hemifacial spasm in an involuntary contraction of the expression muscles, with a spontaneous, intermittent or persistent beginning, and variable force and intensity ${ }^{4}$.

The ophthalmologic and neurologic exams are essential to stablish a diagnosis of essential benign spasm or secondary to systemic diseases like in Parkinson disease ${ }^{5}$.

The post paralytic hemifacial spasm is secondary to an aberrant regeneration of new axons of the facial nerve to the facial muscle fibers.

This aberrant innervation produces a nonintentional movement in another area of the face. For example, when smiling the involuntary eyelid closure may be present ${ }^{6}$.

The peripheralneurectomy of facial nerve is considered the more efficient treatment, other mentioned treatments are the alcohol infiltration to produce a chemical necrosis, percutaneous thermolysis or selective avulsion of facial nerve, with the severe secondary adverse effects ${ }^{7,8}$.

Brin and Cols. mention a series of cases for the treatment of hemifacial spasm by the infiltration of botulin toxin, describing an improvement in $93.1 \%$ of periocular and perioral spasms, with an effect for 17.4 weeks $^{9,10}$.

The actual treatment for hemifacial spasm includes an electromyography to measure the motor unit activation and the electric variation after infiltration of botulin toxin.

Botulinum toxin type A was introduced by Dr. Allen Scott in the late 60 's, being a derived obtained from Clostridium botulinum. The action mechanism is the blockade of acetylcholine release from the presynaptic motor nerve unit. ${ }^{4}$

The contraindications for application of Botulin toxin are rare because is a drug classified as $\mathrm{C}$ category and their use is contraindicated during pregnancy, breastfeeding and neuromuscular diseases as myasthenia gravis, Eaton-Lambert syndrome and lateral amyotrophic sclerosis. This drug must be administered carefully in patients with consume of aminoglycosides, tetracycline, polymyxins, penicillin, anticholinesterases, and calcium channel blockers, because this may alter the conduction in the neuromuscular union ${ }^{4,5,9}$. 
According to other studies, the electromyography is very useful to identify the correct place and dose of botulin toxin administered, allowing us to control and follow up the involuntary muscular activity in a practical and safe way ${ }^{8,10-12}$.

\section{Conclusions}

The therapeutic results depend on the correct diagnosis, an electromyography test to select the affected muscles and allow a correct infiltration of the precise doses to obtain an effective treatment. The empiric application of botulin toxin in facial and cervical muscles must be avoided, we suggest to guide the treatment with the electromyography registry to control the precise doses and obtain the better results.

The latency for type a botulin toxin is one week and it last 4 to 8 weeks, with a limit for administration of 1 dose each 12 weeks to avoid develop of antibodies against the toxin.

\section{REFERENCES}

[1] MichaelJ. Aminoff, Clinical Electromyography, Aminoff's Electrodiagnosis in Clinical Neurology. Sixth Edition, San Francisco, CA, Elsevier.2012

[2] Martínez, F. Wajskopf, S. Espasmo Hemifacial. Arch Neurocien (Mex). Vol. 11, No. 4: 288301, 2006

[3] M.K. Childers, The importance of electromyographic guidance and electrical stimulation for injection of botulinum toxin, Phys Med RehabilClin N Am 14 781-792. 2003
[4] Glenn T. Clark, The management of oromandibular motor disorders and facial spasms with injections of botulinum toxin, Phys Med RehabilClin N Am 14 pags. 727-748. 2003

[5] H.A. Jinnah, Stewart A. Factor,Diagnosis and Treatment of Dystonia,NeurolClin 33 77-100. 2015

[6] Botman, J. W.; Jongkness, L. B. W. - The results of intratemporal treatment of facial palsy. Pract Otorrhinolaringol.17: 80-100, 1975.

[7] Scott R. Gibbs, MD, and Andrew Blitzer, botulinum toxin for the treatment of spasmodic dysphonia, otolaryngologic clinics of north America, volume 33 number 4, 2000.

[8] Sagar, Mark, and Remington Scott. "System and method for tracking facial muscle and eye motion for computer graphics animation." U.S. Patent No. 7,554,549. 30 Jun. 2009.

[9] Samuel M. Lam, The basic science of botulinum toxin, Facial PlastSurgClin N Am 11 pags. 431-438. 2003

[10] Bhupendra C.K. Patel, FRCS, FRC, surgical management of essential blepharospasm, otolaryngolClin N Am 38, 1075-1098. 2005

[11] Padua G, Guarderas J, Rodríguez D, Zaldivar I, Espinoza E. Procedimiento para la rehabilitación de Sinkinesismediante la técnica de retroalimentaciónBiológicaelectromiográfica. Rev Mex Psicol1994; 11(1):19-23.

[12] Rodríguez M, Mangas S. Ortiz G, Et Al. Rehabilitación de sincinesia y asimetría facial enpacientes con parálisis facial periférica con la técnica de biofeedback electromiográfico. Arch Neurocien (Mex) Vol. 16, No. 2: 69-74; 2011.

Citation: Carrillo Rivera Jorge Arnulfo et al. Electromyography Diagnosis and Treatment with Botulin Toxin for Hemi facial Post Paralytic Spasm, Case Report. ARC Journal of Surgery.2017; 3(3): 1-4. doi: dx.doi.org/ 10.20431/2455-572X. 0303001.

Copyright: (C) 2017 Authors. This is an open-access article distributed under the terms of the Creative Commons Attribution License, which permits unrestricted use, distribution, and reproduction in any medium, provided the original author and source are credited. 